\title{
Extending the Scope of Representation Theory: A Review and Proposed Research Model
}

\author{
Jan Recker \\ Business Process Management Group, \\ Queensland University of Technology \\ email: j.recker@qut.edu.au \\ Michael Rosemann \\ Business Process Management Group, \\ Queensland University of Technology \\ email: m.rosemann@qut.edu.au \\ Peter Green \\ UQ Business School, University of Queensland \\ email: p.green@uq.edu.au \\ Marta Indulska \\ UQ Business School, University of Queensland \\ email: m.indulska@business.uq.edu.au
}

\begin{abstract}
This paper reflects on a popular and influential theory unique to information systems (IS), namely representation theory, which is widespread in research on conceptual modelling. We review scholarly work in this domain and discuss why and how studies using representation theory need to transcend their focus of research and link their findings to further consequential variables of interest. We propose an innovative research design that builds upon, and converges, representation theory and the established technology acceptance model as an example for an extended study. We conclude by discussing how the example of this research study may inspire IS researchers to overcome traditional theory boundaries and converge rather than diverge existing approaches to IS research in related domains.
\end{abstract}




\section{Introduction}

The information systems discipline is relatively new. It evolved at the intersection of historically well-established research fields such as management science, computer science, organisational theory and others (Vessey et al., 2002). Researchers studying in the IS area have mostly originated from one of these reference disciplines, bringing with them not only a range of methods and methodologies but also a diversity of underlying philosophical assumptions about research and, going deeper, regarding understanding and cognition of reality, language and truth. However, since we understand our discipline is concerned with 'the effective design, delivery, use and impact of information technology in organisations and society' (Avison and Fitzgerald, 1995), we feel that it is quite uniquely placed at the interface of technology and organisation, unlike some of its foundational or reference disciplines. That is, it addresses the interaction in human-machine systems (Lee, 2001).

The evolution of IS research since its inception has led to the consequence that most of the theories used stem from its reference disciplines. Overall, a wide range of distinctly different foundational theories is being used in IS research, leading to considerable diversity (Robey, 1996; Vessey et al., 2002; Benbasat and Zmud, 2003) and the coining of the term 'fragmented adhocracy' (Banville and Landry, 1989) as a description of it. This has also resulted in an ongoing quest for a cumulative tradition, in the hope of evolving a research discipline that builds on an existing body of knowledge, has an awareness of the remaining open challenges, and is guided by a methodological procedure in its future research efforts (Kuhn, 1962; Keen, 1980; Weber, 1997).

The ongoing debate about what constitutes the IS field has centred on the question of what are the core theories unique to information systems that define the discipline and, from a broader perspective, its body of knowledge (Benbasat and Weber, 1996). The argument used in this context is that a reliance on foundational theories from reference disciplines distracts from the main game - namely, identifying, articulating and foremost of all, researching core phenomena that give IS its identity (Weber, 1987). In other words, unless the IS discipline evolves based on a unique core that comprises topics, theories and methodologies, there is a danger of it remaining an intellectual convocation of individuals that pledge allegiance to other disciplines while studying phenomena nominally ascribed to information systems (King, 1993).

Looking at how to address this, Benbasat and Weber (1996) identify three types of diversity, these being diversity in the phenomena that are being studied, diversity in the theoretical foundations that guide such studies, and diversity in the research methods used to study them.

In this paper we reflect on progress in a dedicated subset of the IS field, addressing selected instances of these three types of diversity. We focus on 
conceptual modelling and its associated phenomena, an area that is widely regarded as inseparable from IS development (Kottemann and Konsynski, 1984; Karimi, 1988). It also has repeatedly been proposed as one of the core artifacts in IS research overall (Weber, 1997; Frank, 1999). In terms of theoretical foundations, we look at the emergence of a promising candidate for conceptual modelling theories, namely models of representation (Wand and Weber, 1990, 1993, 1995) that are referred to as representation theory. In terms of research methods we investigate the principles of representational analysis (Rosemann et al., 2004), also referred to as ontological analysis.

The aim of our paper is to assess the current state of research in this specific domain and to give guidance on how to progress this state. While models of representation and the process of representational analysis per se have been shown to result in interesting and relevant findings, there remains a need for these studies to transcend their current research scope. We argue that representation theory and associated research efforts can be further advanced to exert a wider influence on information systems if this stream of research is put into a broader context by studying the impact of the findings on further phenomena relevant to our research domain. We recapitulate existing scholarly approaches and then discuss a research design that aims at expanding the scope of representation theory and method of representational analysis by converging it with other IS-specific theories, in this instance, the technology acceptance model.

We proceed as follows. In the next section, the main principles of representation theory and previous work in this area are reviewed, with consideration paid to the scope and focus of the analyses. Following this, we present and discuss a research model that converges representation theory and the technology acceptance model and briefly outline the stages of our research. The paper concludes with a discussion of contributions and guidance on how fellow researchers may extend the scope of the theory and related method.

\section{Conceptual modelling and representation theory}

\section{Models of representation and representational analyses}

Significant attention has been paid to the role that conceptual models play in the process of information systems development (Wand and Weber, 2002). Most of the attention has been directed at the domain of information systems analysis and design (ISAD), which is concerned with the development and engineering of IS artifacts based on the identification, elicitation and documentation of certain domain requirements. In particular, the process of conceptual modelling, that is building a representation of selected phenomena in the problem domain for the purpose of understanding and communication among stakeholders (Kung and Sølvberg, 1986; Mylopoulos, 1992; Siau, 2004), is believed to be an inevitable 
part of requirements engineering (Kottemann and Konsynski, 1984; Karimi, 1988). The quality of conceptual models used in the requirements engineering phase of IS development processes has been shown to have a determining impact on the acceptability and usability of the final IS artifact that is built (Lauesen and Vinter, 2001). As the cost of fixing errors grows exponentially with the elapsed time to discovery during the implementation process (Moody, 1998), an adequate problem domain representation through conceptual models may reveal errors such as faulty requirements specifications in an early stage of the IS development.

Conceptual modelling, as such, is a well-researched subject in IS (Wand and Weber, 2002). However, the majority of past studies have focused on the development of new approaches to conceptual modelling (Punter and Lemmen, 1996; Galliers and Swan, 2000) rather than on the critical evaluation and improvement of existing approaches (Moody, 2005). Several researchers state that there is a need to shift academic resources from development to evaluation and to strive for progress in the field of theoretical foundations and quality frameworks for conceptual modelling (Oei et al., 1992; Punter and Lemmen, 1996; Galliers and Swan, 2000; Wand and Weber, 2002; Moody, 2005).

Researchers are evidently concerned that the lack of rigorous and mature theoretical foundations for conceptual modelling can result in the development of information systems that are unable to completely capture relevant phenomena in their real world domains (Wand and Weber, 1995). This concern stems from the observation that, during requirements engineering for information systems development, modellers are confronted with the need for a conceptual structure on which to base the representation of requirements. The criticism has always been the lack of theories that provide conceptual modelling activities with such structures. In fact, most of the existing approaches for modelling have been developed on the basis of practical wisdom rather than on a scientific theory (Bubenko, 1986).

Over time, a number of approaches have been proposed to present theoretical guidance for the development, evaluation and use of conceptual modelling (e.g. Siau et al., 1996; Falkenberg et al., 1998; Agerfalk and Eriksson, 2004; Rockwell and Bajaj, 2004). Most notable are the approaches based on theories of ontology (e.g. Milton and Kazmierczak, 2004; Guizzardi, 2005), and especially the work of Wand and Weber $(1990,1993,1995)$ towards a theory of representation, derived from an ontology defined by Bunge (1977), that became widely known as the Bunge-Wand-Weber representation model.

Generally, ontology studies the nature of the world and attempts to organise and describe what exists in it, in terms of the properties of, the structure of, and the interactions between real-world things (Bunge, 1977; Shanks et al., 2003). As computerised information systems are representations of real world systems, 
Wand and Weber suggest that ontology can be used to help define and build information systems that contain the necessary representations of real world constructs. Yet, the philosophical nature of theories of ontology and their terminology and overall scope are not very conducive to application in the context of information systems or, more specifically, conceptual modelling. Thus, it was Wand and Weber's (1990, 1993, 1995) adoption of an ontology defined by Bunge (1977) that facilitated the wider uptake of this theoretical model within the information systems community. The Bunge-Wand-Weber set of models actually comprises three models (Wand and Weber, 1995; Weber, 1997); the representation model, the state-tracking model and the decomposition model. However, it is mainly the representation model that has been used in IS research.

The BWW representation model (henceforth referred to simply as the BWW model') specifies a number of constructs for which conceptual modelling languages that purport to model information systems domains need to provide representations. Some minor model alterations have been carried out over the years by Wand and Weber $(1993,1995)$ and Weber (1997), but the key constructs of the BWW model can be grouped into the following clusters: things including properties and types of things; states assumed by things; events and transformations occurring on things; and systems structured around things (refer to Weber, 1997 and Rosemann et al., 2006 for a complete list of constructs and clusters).

The BWW model has over recent years achieved significant levels of scholarly attention and dissemination, as is indicated by well over one hundred publications drawing on it in contexts such as comparison of modelling languages (Rosemann et al., 2006), modelling language foundations (Wand et al., 1995), model quality measurement (Gemino and Wand, 2005) and method engineering (Wand, 1996). Aside from its demonstrated usefulness in studies of phenomena associated with conceptual modelling, the BWW model has also been used in related research domains, for instance in studies on information systems requirements engineering (Soffer et al., 2001).

Most notably, however, the BWW model is used as a reference benchmark for the representational analysis of conceptual modelling languages in order to determine their representational capabilities and deficiencies. In this process, the constructs of the BWW representation model (e.g. thing, state, transformation) are compared with the language constructs of the modelling language (e.g. event, activity, actor). The basic assumption is that any deviation from a 1-1 relationship between the constructs in the representation model and the corresponding constructs in the modelling language leads to a situation of representational deficiency in the language, potentially causing confusion for its users. Two principal evaluation criteria may be studied: ontological completeness and 
ontological clarity. The study of ontological completeness is the analysis of the extent to which a modelling language has a deficit of constructs mapping to the set of constructs proposed in the BWW representation model. The study of ontological clarity involves the analysis of the extent to which the modelling language constructs are deemed overloaded (i.e. they map to two or more constructs in the BWW model), redundant (i.e. two or more language constructs map to the same construct in the BWW model), or excess (i.e. they map to none of the constructs in the BWW model (see Figure 1).

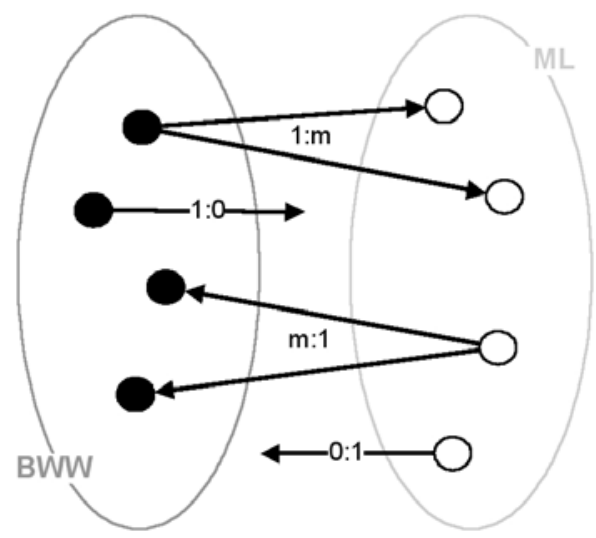

\begin{tabular}{|c|l|}
\hline \multicolumn{2}{|c|}{ Key } \\
\hline BWW & $\begin{array}{l}\text { Set of constructs described in the } \\
\text { BWW model } \\
\text { Set of constructs comprising the } \\
\text { Modelling Language } \\
\text { Construct described in the BWW } \\
\text { model } \\
\text { Modelling language construct }\end{array}$ \\
\hline
\end{tabular}

Figure 1: Types of potential representational deficiencies (Weber, 1997).

In terms of procedural guidelines, Rosemann et al. (2004) discussed how the method of representational analysis has, over time, been refined and revised to achieve higher levels of research maturity.

\section{A research review: identifying the scope of analysis}

Similar to the widespread acceptance of the BWW representational model in IS research, the research method of representational analysis has also gained wide-spread dissemination in studies related to conceptual modelling (Green and Rosemann, 2004). It has, in several instances, been shown to deliver insights into features and shortcomings of languages that purport to model real world domains. Due to space restrictions, we here limit our review of such studies to a discussion of selected examples of BWW-based studies of phenomena associated with various conceptual modelling languages.

Wand and Weber (1993) discussed the general applicability of the BWW model of the representational capability of conceptual modelling languages through their evaluation of the Entity-Relationship modelling language. The study comprised an analytical evaluation of the ER language constructs with respect to the achieved levels of ontological completeness and ontological clarity. From their analysis, Wand and Weber concluded that the BWW model provides the 
rudiments of a theory that can facilitate systematic insights into the nature and use of modelling languages.

Green and Rosemann (2000) used the BWW model to analyse the Event-Driven Process Chain (EPC) notation, focusing on both ontological completeness and clarity. Their findings have been empirically validated through interviews and surveys (Green and Rosemann, 2001). In a second iteration of their empirical study, Green and Rosemann (2002) identified the modelling role (e.g. business analyst, technical analyst), that the modelling subject occupies in the modelling initiative, as a contingency variable that moderates the perceived criticality of identified representational deficiencies. The role that the modelling subject occupies determines the views that he or she takes towards conceptual models. For instance, some interviewees questioned by Green and Rosemann (2002), who had a need for considering multiple modelling views (e.g. data, process, function, organisation) due to their role in the modelling initiative, perceived representational deficiencies with respect to construct redundancy as less critical than respondents that occupied a different modelling role. For them, seemingly redundant constructs provided the benefit of complexity reduction rather than being a deficiency.

Further empirical studies on the EPC notation with the help of the BWW model by Davies et al. (2004) found that the modelling experience also explains some of the variations between responses for each of the representational deficiencies explored. Less experienced modellers often have not yet encountered modelling scenarios in which certain representational deficiencies would induce problems in the use of the language. For instance, if a modeller has not used a potentially ambiguous language construct, he or she would not know how critically that deficiency would impact his or her modelling. Similarly, more experienced modellers often have an array of work-arounds for modelling problems they have encountered in their work and are thereby able to overcome deficiencies that may be critical without such work-arounds.

The same study found empirical support for the contingency effect of the modelling purpose that was earlier hypothesised by Rosemann and Green (2000) to also moderate the perceived criticality of representational deficiencies. Modelling purposes (e.g. workflow engineering, systems specification, business requirements documentation) determine representational requirements of a model. In the area of process modelling, for instance, workflow engineering has the requirements of sound and precise process models without deadlocks or starvation areas (Kiepuszewski et al. 2003). These requirements are, however, of less relevance to business requirements documentation purposes, which drive a different set of representation needs that a model has to meet.

The study of the BPMN language by Recker et al. (2006) found empirical evidence for the proposition that the modelling tool in which a modelling language is 
implemented can have the capacity to countervail some representational deficiencies. That is, the extent of tool support for a given modelling language can moderate the criticality of its representational deficiencies. For instance, Recker et al. (2006) found that deficiencies in BPMN with regard to the decomposition of models and processes were often not experienced as such due to support provided by the tool in the form of a model repository and object links.

In line with the findings of Davies et al. (2004), the study by Recker et al. (2006) further found that, in modelling practice, language users often do not use the modelling language in its original version. Instead of using a 'vanilla' specification of a language, organisations often follow a set of modelling conventions that restricts the set of language constructs to be used and sometimes even applies new meanings to particular constructs. Consequently, in cross-organisational studies, consideration has to be paid to the fact that modelling conventions may restrict or alter the original specification of a language, which in turn may have an impact on its representational capabilities and the way that language users perceive potential deficiencies.

The BWW model has also been used to explore representational deficiencies of object-oriented modelling languages such as OML (Opdahl and Henderson-Sellers, 2001) and UML (Opdahl and Henderson-Sellers, 2002). Both evaluations remain on an analytical level and investigated the completeness and clarity of the language specifications. Similar to Green and Rosemann (2001), Opdahl and Henderson-Sellers point out the moderating effect that different modelling purposes (e.g. representing a problem domain versus representing the proposed structure of information systems) may have on the criticality of a representational deficiency of the language.

As an example of work that explores representational deficiencies of modelling languages in combination, Green et al. (2004) analytically examined the ontological completeness of four leading standards for enterprise system interoperability, including BPEL4WS v1.1, BPML, WSC, and ebXML v1.1. A minimal ontological overlap (MOO) analysis (Wand and Weber, 1995; Weber, 1997) has been conducted in order to determine the set of modelling standards exhibiting the minimum number of overlapping constructs but having maximal ontological completeness (MOC) or, in other words, maximum expressiveness. Two different combinations of standards were identified that, when used together, allow for the most expressive power with the least construct overlap. These were ebXML and BPEL4WS, and ebXML and WSCI. The results of the analysis remain to be tested empirically.

Other analyses based on the BWW representation model include further evaluations of schema modelling languages (Weber and Zhang, 1996), structured analysis modelling languages (Rohde, 1995), process modelling languages (Recker 
et al., 2006) and interoperability choreography modelling languages (Green et al., 2005).

In summary, the usefulness of representational analysis is documented by over 30 applications (Green and Rosemann, 2004). However, our brief review shows that while previous findings based on representational analyses have been shown to be of relevance, the scholarly work has mostly focused on the representational capabilities of modelling languages. Capabilities and deficiencies have been identified, or the theorised effects of these deficiencies empirically explored or tested.

After more than two decades and a multitude of such studies, we believe that, in spite of the track record of demonstrated usefulness, the intense focus of previous and current representation theory based scholarly work on the capabilities of modelling languages induces an illusion of research progress when it comes to the building of a cumulative research tradition. Research progress cannot be achieved solely by the production of an abundance of papers more or less replicating the findings of previous representational analyses. In fact, we are concerned that the rich basis of representation theory may get lost in a rather inward looking research stream that retains a high focus on repeating studies using the same methodology for yet another phenomenon or language associated with conceptual modelling.

We do not, however, dispute that several conceptual modelling researchers have ventured beyond this traditional focus. Nevertheless, the majority of existing studies, while contributing to the impressive levels of maturity and dissemination of both theory and method, have remained within the narrow scope of language evaluation. Hence, we see a need for representational analysis to move beyond simply assessing modelling language capabilities. Figure 2 shows how the research scope of representational analysis may be extended beyond the focus of previous studies and also depicts potential dependant variables that may be studied.

The method of representational analysis in general provides a rich theoretical basis of propositions that may be used to study further consequential dependant variables of interest. Wand and Weber themselves saw this opportunity for further research:

In general, future theoretical and empirical research on grammars should investigate their effectiveness or efficiency. ... Empirical work could now be done to determine the impacts, if any, that these deficiencies have on users of these grammars (Wand and Weber, 2002). 


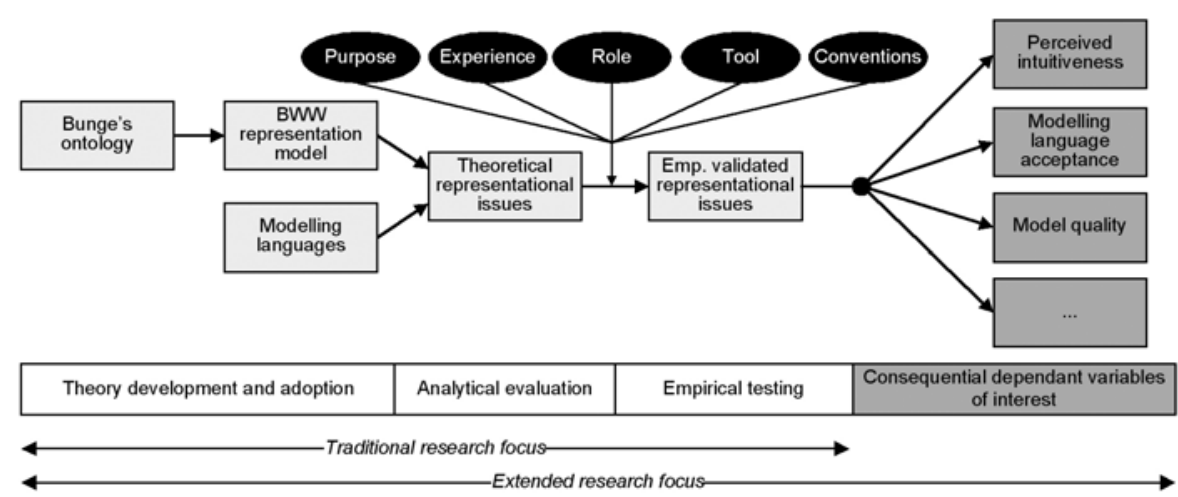

Figure 2: Research method of representational analysis and the quest for the dependent variables.

As an example of a study that addresses further dependant variables, outside of modelling language capabilities, Gemino and Wand (2005) investigated the effects of using optional versus mandatory properties in data models on the complexity and understanding of the resulting model. As another example, Recker et al. (2006) mention the possible need to consider how to derive modelling methodologies based on representational principles. This can, for instance, be achieved by initially modelling using a clear rather than complete set of language constructs to facilitate modelling with lower levels of complexity. In a second iteration this model could then be enriched with a second set of language constructs that add to its completeness, although perhaps at the cost of increased construct overload, redundancy or excess. As Figure 2 indicates, other interesting aspects to study are the effect of validated representational propositions (e.g. language constructs should not be overloaded) on the perceived intuitiveness of the resulting model, as well as factors arising from construct excess. In order to study the latter with respect to, for example, model quality (e.g. perceived understandability, effectiveness for problem solving or domain comprehension tasks), models that contain language constructs that the theory indicates to be unclear in nature and purpose (Weber, 1997) can be compared in laboratory experiments with models that do not contain excess constructs. Obviously, many other endogenous variables potentially contribute to the outcomes of such studies. The framework on conceptual modelling proposed by Wand and Weber (2002) that distinguishes the modelling language from the modelling method and the resulting model may be used as a starting point for identifying areas of evaluation in which potential causal relationships (e.g. language - model, language - method) have not yet been fully explored.

We see the potential to identify and integrate further related theories used in the information systems discipline in such studies. As a result, the state of 
research could be advanced by means of creative and novel theory adaptations and applications that have not yet been envisaged. In summing up, we observe that many stimulating research challenges stem from the principles of representation theory and representational analysis. In our own research we have sought to take on some of these challenges. In the next section we briefly outline a research model that is designed to study the consequences that representational capabilities have on the user acceptance of a modelling language.

\section{A proposed research model}

Stemming from Wand and Weber's (2002) comments on the need to study the impact of representational deficiencies on the effectiveness, usefulness and/or efficiency of a modelling language, we have sought to study the impact of ontological completeness and clarity on the perceived usefulness and ease of use of a language. As such, we have restricted our investigation in the sense that we do not consider other related phenomena such as, for instance, the quality of the model produced. We acknowledge that other areas of evaluation remain in which the consequences of representational deficiencies still need to be explored.

In this context of acceptance, the technology acceptance model (TAM) (Davis, 1986, 1989) postulates, and it has been shown in an extensive number of empirical studies, that perceived usefulness (PU) and perceived ease of use (PEOU) of an IS artifact directly influence an individual's intention to use that IS artifact (Davis, 1989; Davis et al., 1989; Moore and Benbasat, 1991). Such intention in turn has been found to accurately predict the actual use of the artifact (Davis et al., 1989; Venkatesh and Davis, 1996).

Hence, we see an opportunity to converge, if not amalgamate, two of the most influential approaches to IS research. The extensive amount of research related to TAM has reportedly made it one of the most influential and commonly employed IS models (Lee et al., 2003; King and He, 2006). Its advantages include the parsimony and explanatory power of the model (Venkatesh and Davis, 2000) and the well-researched and validated measurement inventory with high levels of reliability and validity of constructs and measurement scales (Davis, 1989; Segars and Grover, 1993). The large number of TAM studies will not be recapitulated here; instead the reader is referred to an annotated overview such as that given in, for instance, Lee et al., (2003). One interesting point, however, must be made. King and He (2006) found in their rigorous meta-analysis of TAM that, despite its recent adaptations to, for example, the method context (Moody, 2003), extensions such as the TAM2 model (Venkatesh and Davis, 2000), and revisions such as the UTAUT model (Venkatesh et al., 2003), the original model nevertheless is of high reliability, has good explanatory power and obtains high levels of robustness. We therefore deem TAM, in its original form, a suitable starting point for our line of investigation. 
The interesting observation to be made with respect to representation theory is that TAM specifies a general model of IS acceptance that needs to be tailored to the specific research context (Fichman, 1992). As we, in our research, are concerned with conceptual modelling and the languages used for such efforts, we see an opportunity to link these two theories to study the acceptance of modelling languages. Along similar lines, Venkatesh and Davis (1996, 2000) argue that it is necessary to better understand the determinants of PU and PEOU since the generality of TAM, which allows for wide applicability, induces a lack of focus on the particular artifact under observation. Accordingly, we explicitly explore the determinants of PU and PEOU in the context of conceptual modelling languages by drawing on the principles of representational analysis.

Starting with PU, Moody (2003) argues that the original definition of PU (Davis, 1989) must be extended to reflect the objectives of the particular task for which the artifact is being used. Adopting this insight in the context of conceptual modelling, we can perceive PU as 'the degree to which a person believes that a particular language will be effective in achieving the intended modelling objective'. This definition reflects the notion of rational selection (Rescher, 1973), which states that, generally, those methods will be adopted that outperform others or are more effective in achieving intended objectives. Based on this understanding, we can argue that 'good' languages are those that contain all the constructs needed to produce complete representations of the relevant phenomena in a real-world domain of interest (Weber, 1997). Clearly, the notion of a complete language (without construct deficit) reflects the notion of an effective language with respect to the objective of conceptual modelling to build a representation of selected phenomena in the problem domain (Mylopoulos, 1992; Wand and Weber, 2002; Siau, 2004). Accordingly, we urge that ontological completeness is a determinant of the PU of a conceptual modelling language (see Figure 3), based on the argument that PU represents a perceptual judgment of an artifact's effectiveness (Rescher, 1973).

PEOU, adapting its original definition in Davis (1989) to the context of conceptual modelling, can be understood as 'the degree to which a person believes that using a particular language will be free of effort'. Modelling 'free of effort' means modelling without complexity (Gemino and Wand, 2005), which in turn provides another link to representation theory. Weber (1997) argues that, in addition to the question of 'what' can be represented, also the question of 'how' it can be represented is of importance. He says that the clarity of a language is determined by how unambiguously the meaning of its constructs is specified and thus how much effort is needed to apply desired real-world meaning to them. The notion of clarity embraces the three situations of construct overload, redundancy and excess. That is, a formative relationship exists between these sub-constructs and the overall construct of ontological clarity. Again, one can perceive a link between the notion of clarity of a language and PEOU of a language with respect 
to the aim of conceptual modelling to facilitate communication and understanding among stakeholders (Mylopoulos, 1992; Wand and Weber, 2002; Siau, 2004). Consequently, we argue that ontological clarity is a determinant of PEOU of a language (see Figure 3).

Aside from these primary constructs of the research model, in every scientific study it is necessary to identify and take into account endogenous variables that potentially impose a strong contingent effect on the independent variable dependent variable' relationship. Moderating variables must be identified based on the context (Fichman, 1992). We draw on variables that have previously been identified, and validated, as having consequences for our particular research context. Previous representational analyses of process modelling languages (see above) have identified and explored the contextual factors of modelling role, modelling purpose, modelling tool, modelling conventions and modelling experience, all of which can moderate the perceived criticality of representational deficiencies, and which we therefore include in our model (see Figure 3).

Aside from these contextual factors, we also draw on one of the most frequently noted limitations of previous TAM studies, namely the impact of 'voluntariness' on adoption decisions. Moore and Benbasat (1991) first recognised that the acceptance behaviour of individuals may be influenced by a mandate from superiors, which is expressed as a moderating effect of a variable 'voluntariness'. This has been included in some studies (e.g. Venkatesh and Davis, 2000; Venkatesh et al., 2003). In the case of conceptual modelling, we note that in most cases the use of a particular modelling language is indeed mandated in organisations by superiors such as modelling coaches, consultants or other influential individuals. Accordingly, we argue that the extent of voluntariness impacts the causal relationship between the intention to use a modelling language and the actual usage of the language.

Figure 3 shows the overall research model, adapted to our selected research case of the BPMN modelling language. In previous work (Recker et al., 2006) we have identified and empirically tested representational deficiencies of BPMN with respect to construct deficit, redundancy, overload, and excess, and these results will now be used to derive measurement items for each representational deficiency. 


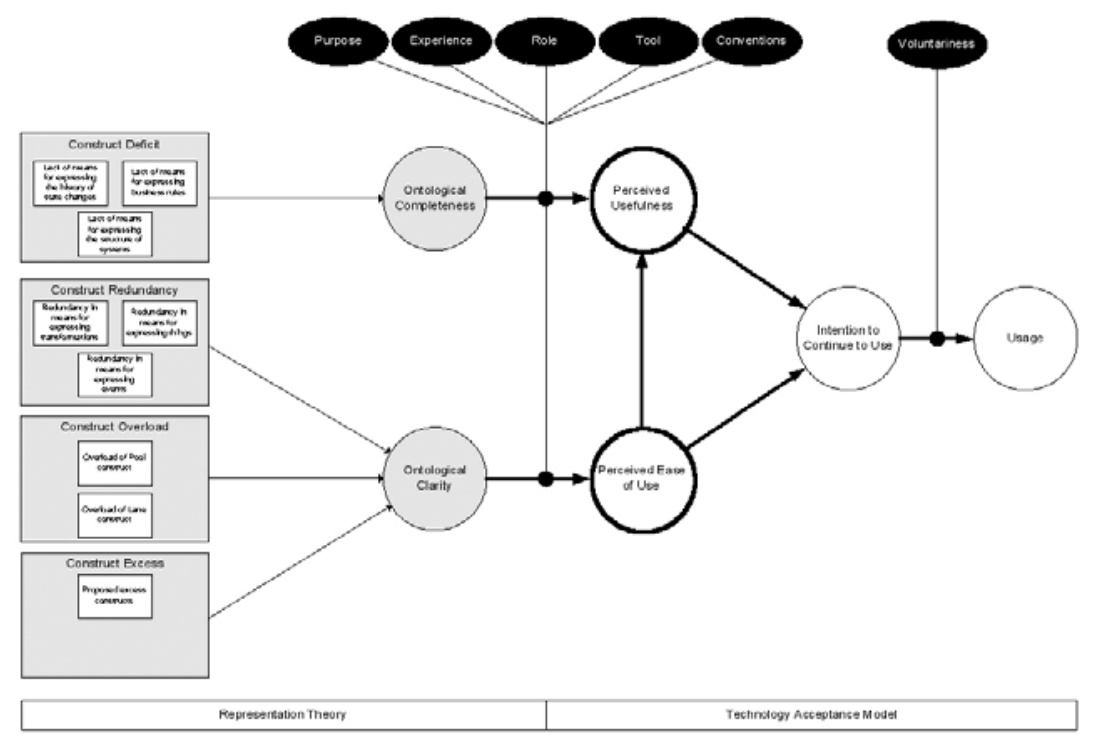

Figure 3: Proposed research model in the context of the BPMN process modelling language.

After the formulation of the research model we need to operationalise the hypotheses and measurement items contained in the model to create an empirical instrument with which to test it. The level of dissemination and maturity of TAM, and its measurement inventory, allows us to develop an appropriate instrument by adopting existing measurement scales to the context of process modelling languages. Nevertheless, this task still poses a number of challenges. Most significantly, several researchers have noted limitations related to the conceptualisation of 'usage' (DeLone and McLean, 2003) and the use of self-reported measurements (Lee et al., 2003). Also, the definition of 'intention to use' must be slightly modified to 'intention to continue to use'. This adaptation reflects the fact that only when a modelling individual has started using a language for modelling tasks is he or she able to explore its potential representational deficiencies and form an opinion about its usefulness and ease of use. Second, we will convert the measurement instrument to a web-based survey and distribute it to both actual and potential adopters of BPMN. In order to account for the fact that user perceptions and intentions may change over time (Lee et al., 2003) we will also add a longitudinal aspect to the study by measuring these quantities at two points in time: (a) in a period of early adoption and exposure to BPMN, and (b) in a later period of increased familiarity with the modelling language. This should allow us not only to counter the criticism of most acceptance studies that they are restricted to cross-sectional studies (Agarwal and Karahanna, 2000), but also account for, and further explore, the moderating effect of modelling experience on representational deficiencies and 
their impact on language acceptance. Also, it should allow us to study the impact of representational deficiencies not only on an individual's early intention to start to use a modelling language but also on the decision to continue to use it after a period of prolonged exposure. Finally, a web-based format of the instrument permits the gathering of data from a multitude of potential respondents across different regions and cultures, thereby overcoming the bias of restricted contextual settings and supporting potential cross-contextual analyses as well.

We would like to note here an obvious limitation of this proposed research. The presented study draws heavily on the principles of representation theory and TAM. Hence, the focus of study is restricted by the filtering lenses that these models employ. Accordingly, the research model may lack other, potentially relevant, endogenous variables that may also affect user acceptance of modelling languages. Nevertheless, the scope of the proposed model enables us to focus work on gaining insights into the expressiveness of the combination of the two theories, and to thereby avoid the necessity to translate findings from different theoretical bases.

\section{Contributions and outlook}

This paper has reviewed and discussed the state of progress of IS research using representation theory. We have argued that models of representation provide a mature theoretical basis for scholars researching conceptual modelling artifacts and activities. However, the state of progress in this particular area of research has mostly remained at the level of assessing various language capabilities and the argument in this paper is that the underlying representation theory provides a fruitful basis to transcend this level of investigation to study further phenomena of interest associated with conceptual modelling. In fact, it is time researchers moved outside the confines of traditional studies. Some prior research, such as the work by Gemino and Wand (2003, 2005), serve as stimulating examples for studies that use the richness of the theory to derive research hypotheses over and above the level of language capabilities. In our own research we aim to further transcend this research horizon and to progress the state of maturity and dissemination of representation theory and representational analysis. With this aim in mind, we have outlined an example of research that links propositions and findings from representation theory with other theories in our discipline, namely the issue of acceptance of IS artifacts.

In future work we aim to continue along two lines of investigation in particular. Firstly, we will continue our work on the acceptance of modelling languages. At present we are developing and testing a measurement scales inventory to conduct empirical studies on the adoption and acceptance of modelling languages in order to test the hypothesised relationships in our research model shown above. Secondly, in a related stream of research, we will continue our work on 
the effect of representational deficiencies on the quality of the models produced. As part of this work, we have evaluated and empirically confirmed representational deficiencies of a selected process modelling language and communicated our findings to the developers of that language in order to influence a revision of the language specification. After distribution of the revised process modelling language specification, we will, as a last step in the research, assess and compare the quality of business process models produced using the revised modelling language with those produced using the pre-revision version of the language.

As a concluding remark, we would like to add that we have found the research method of representational analysis very useful in understanding and exploring the challenges related to conceptual modelling and we expect this type of research to continue to give stimulating input to both academic and practical work in the area of conceptual modelling in the future.

\section{References}

Agarwal, R. and Karahanna, E. 2000, 'Time flies when you're having fun: Cognitive absorption and beliefs about information technology usage', MIS Quarterly, vol. 24, no. 4, pp. 665-94.

Agerfalk, P. J. and Eriksson, O. 2004, 'Action-oriented conceptual modelling', European Journal of Information Systems, vol. 13, no. 1, pp. 80-92.

Avison, D. E. and Fitzgerald, G. 1995, Information Systems Development: Methodologies, Techniques and Tools. London: McGraw-Hill.

Banville, C. and Landry, M. 1989, 'Can the field of MIS be disciplined?', Communications of the ACM, vol. 32, no. 1, pp. 48-60.

Benbasat, I. and Weber, R. 1996, 'Research Commentary: Rethinking "Diversity" in Information Systems Research', Information Systems Research, vol. 7, no. 4, pp. 389-99.

Benbasat, I. and Zmud, R. W. 2003, 'The identity crisis within the IS discipline: Defining and communicating the discipline's core properties', MIS Quarterly, vol. 27, no. 2, pp. 183-94.

Bubenko, J. A. 1986, 'Information systems methodologies - A research view', in Olle, T. W., Sol, H. G. and Verrijn-Stuart, A. A. (eds), Information Systems Design Methodologies: Improving the Practice, Amsterdam: NorthHolland, pp. 289-318.

Bunge, M. A. 1977, Treatise on Basic Philosophy Volume 3: Ontology I - The Furniture of the World, Dordrecht, The Netherlands, Kluwer Academic Publishers. 
Davies, I., Rosemann, M. and Green, P. 2004, 'Exploring proposed ontological issues of ARIS with different categories of modellers, Proceedings of the 15th Australasian Conference on Information Systems, Hobart, Australia.

Davis, F. D. 1986, 'A technology acceptance model for empirically testing new end-user information systems: Theory and results', Doctoral dissertation, MIT Sloan School of Management, Boston, Massachusetts.

Davis, F. D. 1989, 'Perceived usefulness, perceived ease of use, and user acceptance of information technology', MIS Quarterly, vol. 13, no. 3, pp. 31940 .

Davis, F. D., Bagozzi, R. P. and Warshaw, P. R. 1989, 'User acceptance of computer technology: A comparison of two theoretical models', Management Science, vol. 35, no. 8, pp. 982-1003.

DeLone, W. H. and McLean, E. R. 2003, 'The DeLone and McLean model of information systems success: A ten-year update', Journal of Management Information Systems, vol. 19, no. 4, pp. 9-30.

Falkenberg, E. D., Hesse, W., Lindgreen, P., Nilsson, B. E., Oei, J. L. H., Rolland, C., Stamper, R. K., van Assche, F. J. M., Verrijn-Stuart, A. A. and Voss, K. 1998, A Framework of Information System Concepts. The FRISCO Report, Web version: <http://www.mathematik.uni-marburg.de/ hesse/papers/fri-full.pdf $>$, International Federation for Information Processing WG 8.1.

Fichman, R. G. 1992, 'Information technology diffusion: A review of empirical research', Proceedings of the 13th International Conference on Information Systems, Dallas, Texas, pp. 195-206.

Frank, U. 1999, 'Conceptual modelling as the core of the information systems discipline - Perspectives and epistemological challenges', in Haseman, W. D. and Nazareth, D. L. (eds), Proceedings of the 5th America's Conference on Information Systems, Milwaukee: Association for Information Systems, pp. 695-8.

Galliers, R. D. and Swan, J. A. 2000, 'There's more to information systems development than structured approaches: Information requirements analysis as a socially mediated process', Requirements Engineering, vol. 5, no. 2, pp. 74-82.

Gemino, A. and Wand, Y. 2003, 'Evaluating modelling techniques based on models of learning', Communications of the ACM, vol. 46, no. 10, pp. 79-84.

Gemino, A. and Wand, Y. 2005, 'Complexity and clarity in conceptual modelling: Comparison of mandatory and optional properties', Data and Knowledge Engineering, vol. 55, no. 3, pp. 301-26. 
Green, P. and Rosemann, M. 2000, 'Integrated process modelling. An ontological evaluation', Information Systems, vol. 25, no. 2, pp. 73-87.

Green, P. and Rosemann, M. 2001, 'Ontological analysis of integrated process models: Testing hypotheses', Australian Journal of Information Systems, vol. 9, no. 1, pp. 30-8.

Green, P. and Rosemann, M. 2002, 'Perceived ontological weaknesses of process modelling techniques: Further evidence', in Wrycza, S. (ed.), Proceedings of the 10th European Conference on Information Systems, Gdansk, pp. 312-21.

Green, P. and Rosemann, M. 2004, 'Applying ontologies to business and systems modelling techniques and perspectives: Lessons learned', Journal of Database Management, vol. 15, no. 2, pp. 105-17.

Green, P., Rosemann, M. and Indulska, M. 2005, 'Ontological evaluation of enterprise systems interoperability using ebXML', IEEE Transactions on Knowledge and Data Engineering, vol. 17, no. 5, pp. 713-25.

Green, P., Rosemann, M., Indulska, M. and Manning, C. 2004, 'Candidate interoperability standards: An ontological overlap analysis, Technical Report, University of Quneensland, Brisbane, Australia.

Guizzardi, G. 2005, Ontological Foundations for Structural Conceptual Models. Enschede, The Netherlands, Telematica Instituut.

Karimi, J. 1988, 'Strategic planning for information systems: Requirements and information engineering methods', Journal of Management Information Systems, vol. 4, no. 4, pp. 5-24.

Keen, P. G. W. 1980, 'MIS research: Reference disciplines and a cumulative tradition', in McLean, E. R. (ed.), Proceedings of the 1st International Conference on Information Systems, Philadelphia, Pennsylvania: ACM Press, pp. 9-18.

Kiepuszewski, B., ter Hofstede, A. H. M. and van der Aalst, W. M. P. 2003, 'Fundamentals of control flow in workflows', Acta Informatica, vol. 39, no. 3, pp. 143-209.

King, J. L. 1993, 'Editorial notes', Information Systems Research, vol. 4, no. 4, pp. 291-8.

King, W. R. and He, J. 2006, 'A meta-analysis of the Technology Acceptance Model', Information and Management, vol. 43, no. 6, pp. 740-55.

Kottemann, J. E. and Konsynski, B. R. 1984, 'Information systems planning and development: strategic postures and methodologies', Journal of Management Information Systems, vol. 1, no. 2, pp. 45-63. 
Kuhn, T. S. 1962, The Structure of Scientific Revolutions. Chicago: Chicago University Press.

Kung, C. H. and Sølvberg, A. 1986, 'Activity modelling and behavior modelling of information systems', in Olle, T. W., Sol, H. G. and Verrijn-Stuart, A. A. (eds), Information Systems Design Methodologies: Improving the Practice, Amsterdam: North-Holland, pp. 145-71.

Lauesen, S. and Vinter, O. 2001, 'Preventing requirement defects: An experiment in process improvement', Requirements Engineering, vol. 6, no. 1, pp. 37-50.

Lee, A. S. 2001, 'Editor's Comments. MIS Quarterly's Editorial Policies and Practices', MIS Quarterly, vol. 25, no. 1, pp. iii-vii.

Lee, Y., Kozar, K. A. and Larsen, K. R. T. 2003, ‘The Technology Acceptance Model: Past, present, and future', Communication of the Association for Information Systems, vol. 12, no. 50, pp. 752-80.

Milton, S. and Kazmierczak, E. 2004, 'An ontology of data modelling languages: A study using a common-sense realistic ontology', Journal of Database Management, vol. 15, no. 2, pp. 19-38.

Moody, D. L. 1998, 'Metrics for evaluating the quality of entity relationship models', Proceedings of the 17th International Conference on Conceptual Modelling — ER '98, Singapore: Springer, pp. 221-5

Moody, D. L. 2003, 'The method evaluation model: A theoretical model for validating information systems design methods', Proceedings of the 11th European Conference on Information Systems, Naples, Italy.

Moody, D. L. 2005, 'Theoretical and practical issues in evaluating the quality of conceptual models: Current state and future directions', Data and Knowledge Engineering, vol. 15, no. 3, pp. 243-76.

Moore, G. C. and Benbasat, I. 1991, 'Development of an instrument to measure the perceptions of adopting an information technology innovation', Information Systems Research, vol. 2, no. 3, pp. 192-222.

Mylopoulos, J. 1992, 'Conceptual Modelling and Telos', in Loucopoulos, P. and Zicari, R. (eds), Conceptual Modelling, Databases, and CASE: An Integrated View of Information System Development, New York, John Wiley and Sons, pp. 49-68.

Oei, J. L. H., van Hemmen, L. J. G. T., Falkenberg, E. D. and Brinkkemper, S. 1992, 'The meta model hierarchy: A framework for information systems concepts and techniques', Tech. Rep. No. 92-17, Department of Informatics, Faculty of Mathematics and Informatics, Katholieke Universiteir, Nijmegen, The Netherlands, pp. 1-30. 
Opdahl, A. L. and Henderson-Sellers, B. 2001, 'Grounding the OML metamodel in ontology', Journal of Systems and Software, vol. 57, no. 2, pp. 11943.

Opdahl, A. L. and Henderson-Sellers, B. 2002, 'Ontological evaluation of the UML using the Bunge-Wand-Weber model', Software and Systems Modelling, vol. 1, no. 1, pp. 43-67.

Punter, T. and Lemmen, K. 1996, 'The MEMA-model: Towards a new approach for Method Engineering', Information and Software Technology, vol. 38, no. 4, pp. 295-305.

Recker, J., Indulska, M., Rosemann, M. and Green, P. 2006, 'How good is bpmn really? insights from theory and practice', Proceedings of the 14th European Conference on Information Systems, Goeteborg, Sweden.

Rescher, N. 1973, The Primacy of Practice, Oxford, UK, Basil Blackwell.

Robey, D. 1996, 'Research Commentary: Diversity in Information Systems research: Threat, promise, and responsibility', Information Systems Research, vol. 7, no. 4, pp. 400-8.

Rockwell, S. and Bajaj, A. 2004, 'COGEVAL: Applying cognitive theories to evaluate conceptual models', in Siau, K. (ed.), Advanced Topics in Database Research. Volume 4, Hershey, Pennsylvania, Idea Group, pp. 25582.

Rohde, F. 1995, 'An ontological evaluation of Jackson's System Development Model', Australian Journal of Information Systems, vol. 2, no. 2, pp. 77-87.

Rosemann, M. and Green, P. 2000, 'Integrating multi-perspective views into ontological analysis', Proceedings of the 21 st International Conference on Information Systems, Brisbane, Australia, pp. 618-27

Rosemann, M., Green, P. and Indulska, M. 2004, 'A reference methodology for conducting ontological analyses, Proceedings of the 23rd International Conference on Conceptual Modelling — ER 2004, Shanghai, China, pp. $110-21$.

Rosemann, M., Recker, J., Indulska, M. and Green, P. 2006, 'A study of the evolution of the representational capabilities of process modelling grammars', Proceedings of the 18th International Conference on Advanced Information Systems Engineering - CAiSE 2006, Luxembourg, Grand-Duchy of Luxembourg, pp. 447-61.

Segars, A. H. and Grover, V. 1993, 'Re-examining perceived ease of use and usefulness: A confirmatory factor analysis', MIS Quarterly, vol. 17, no. 4, pp. 517-25. 
Shanks, G., Tansley, E. and Weber, R. 2003, 'Using ontology to validate conceptual models', Communications of the ACM, vol. 46, no. 10, pp. 85-9.

Siau, K. 2004, 'Informational and computational equivalence in comparing information modelling methods', Journal of Database Management, vol. 15, no. 1, pp. 73-86.

Siau, K., Wand, Y. and Benbasat, I. 1996, 'Evaluating information modelling methods - A cognitive perspective', Proceedings of the 1st Workshop on Evaluation of Modelling Methods in Systems Analysis and Design, Crete, Greece, pp. M1-M13.

Soffer, P., Golany, B., Dori, D. and Wand, Y. 2001, 'Modelling off-the-shelf information system requirements. An ontological approach', Requirements Engineering, vol. 6, no. 3, pp. 183-99.

Venkatesh, V. and Davis, F. D. 1996, 'A model of the antecedents of perceived ease of use: Development and test', Decision Sciences, vol. 27, no. 3, pp. 451-81.

Venkatesh, V. and Davis, F. D. 2000, 'A theoretical extension of the Technology Acceptance Model: Four longitudinal field studies', Management Science, vol. 46, no. 2, pp. 186-204.

Venkatesh, V., Morris, M. G., Davis, G. B. and Davis, F. D. 2003, 'User Acceptance of information technology: Toward a unified view', MIS Quarterly, vol. 27, no. 3, pp. 425-78.

Vessey, I., Ramesh, V. and Glass, R. L. 2002, 'Research in Information Systems: An empirical study of diversity in the discipline and its journals', Journal of Management Information Systems, vol. 19, no. 2, pp. 129-74.

Wand, Y. 1996, 'Ontology as a foundation for meta-modelling and method engineering', Information and Software Technology, vol. 38, no. 4, pp. 281-7.

Wand, Y., Monarchi, D. E., Parsons, J. and Woo, C. C. 1995, 'Theoretical foundations for conceptual modelling in information systems development', Decision Support Systems, vol. 15, no. 4, pp. 285-304.

Wand, Y., Weber, R. 1990, 'An ontological model of an information system', IEEE Transactions on Software Engineering, vol. 16, no. 11, pp. 128292.

Wand, Y., Weber, R. 1993, 'On the ontological expressiveness of information systems analysis and design grammars', Journal of Information Systems, vol. 3, no. 4, pp. 217-37.

Wand, Y., Weber, R. 1995, 'On the deep structure of information systems', Information Systems Journal, vol. 5, no. 3, pp. 203-23. 
Wand, Y., Weber, R. 2002, 'Research commentary: Information systems and conceptual modelling — A research agenda', Information Systems Research, vol. 13, no. 4, pp. 363-76.

Weber, R. 1987, 'Toward a theory of artifacts: A paradigmatic basis for information systems research', Journal of Information Systems, vol. 1, no. 2, pp. 3-19.

Weber, R. 1997, Ontological Foundations of Information Systems, Coopers and Lybrand and the Accounting Association of Australia and New Zealand, Melbourne, Australia.

Weber, R. and Zhang, Y. 1996, 'An analytical evaluation of NIAM's grammar for conceptual schema diagrams', Information Systems Journal, vol. 6, no. 2, pp. 147-70. 